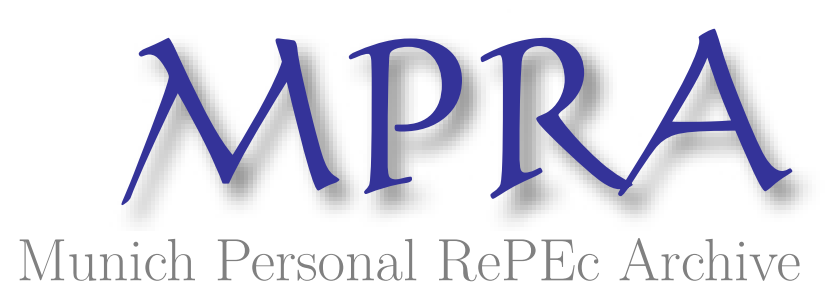

\title{
On the Joint Use of Liability and Safety Regulation
}

Schmitz, Patrick W.

2000

Online at https://mpra.ub.uni-muenchen.de/12536/

MPRA Paper No. 12536, posted 06 Jan 2009 06:25 UTC 


\title{
On the Joint Use of Liability and Safety Regulation
}

\author{
Patrick W. Schmitz \\ University of Bonn, Adenauerallee 24-42, 53113 Bonn, Germany.
}

January 2000

\begin{abstract}
The efficiency of two different means of controlling hazardous economic activities, namely ex post liability for harm done and ex ante safety regulation, is re-examined. Some researchers have stressed that the complementary use of these two instruments can be socially advantageous. Here it is argued that the models which have been built in order to support this view crucially depend on the assumption that there are persistent enforcement errors. It is demonstrated that such a rather unsatisfactory assumption is not needed if wealth varies among injurers.
\end{abstract}

This is the working paper version of the following article: Schmitz, P.W. (2000), "On the Joint Use of Liability and Safety Regulation," International Review of Law and Economics, Vol. 20, pp. 371-382.

I would like to thank Christian Ewerhart, Hans-Peter Grüner, Anke Kessler, Ulrike Malmendier, Georg Nöldeke, Stephanie Rosenkranz, Urs Schweizer, and Dirk Sliwka for helpful discussions. 


\section{Introduction}

A lasting and controversial discussion in the law and economics literature is concerned with the issue of whether tort liability or safety regulation is best suited for controlling accident risks. ${ }^{1}$ Ex post liability and ex ante regulation (safety standards) are generally viewed as substitutes for correcting externalities, and the usual recommendation is to employ the policy which leads to lower administrative costs. However, the phenomenon of complementary use of liability and regulation is widespread in practice. In the United States, for example, there are technological regulations as well as codifications of liability as far as the generation and disposal of hazardous wastes are concerned. ${ }^{2}$ Yet, I am aware of only two papers which try to demonstrate formally that the joint use of liability and regulation can enhance social welfare: Shavell (1984a) and Kolstad, Ulen, and Johnson (1990). While these articles provide valuable insights, they leave some important questions unanswered.

Specifically, Kolstad, Ulen, and Johnson (1990) assume that liability is inefficient due to uncertainty about the court's behavior. This leads to some technical difficulties which are briefly discussed in Ewerhart and Schmitz (1998). What is more important is the fact that Kolstad, Ulen, and Johnson (1990) cannot explain why liability should be used at all, since in their model pure regulation can always implement socially optimal behavior.

In Shavell's (1984a) model, which is more closely related to the analysis in the

\footnotetext{
${ }^{1}$ For early discussions of related issues see Calabresi (1970), Weitzman (1974) and Wittman (1977). Shavell (1984b) provides a comprehensive non-technical analysis of the subject. More recent articles include Rose-Ackerman (1991), Söllner (1994, 1996) and Schwarze (1996).

${ }^{2}$ The Resource Conservation and Recovery Act (1982) imposes technological regulations on the generation of toxic wastes, while under the Comprehensive Environmental Response, Compensation, and Liability Act (1979) victims can sue generators of hazardous wastes for the recovery of compensatory and punitive damages.
} 
present paper, liability is inefficient due to injurers' limited wealth, while regulation is also inefficient because the same regulatory standard applies to all injurers (whereas socially optimal behavior varies among injurers). The fact that in his model a hybrid of liability and regulation can do better than either approach alone crucially relies on his assumption that liability is handicapped by enforcement errors. There is a strictly positive probability that injurers can escape suit, and the magnitude of liability is determined in a suboptimal way. While it is certainly true that courts make mistakes, it seems to be unsatisfactory to base a theory on the assumption that the same kind of error persistently occurs.

In the next section, a convenient variant of the now familiar economic model of tort law is introduced. ${ }^{3}$ It is argued in Section 3 that if injurers cannot escape suit or, more generally, if the magnitude of liability is calculated in an optimal way, it can never be socially advantageous to employ liability and regulation at the same time. This result, which is in stark contrast with Shavell (1984a), is obtained under his original assumption that all injurers face the same wealth constraint.

In Section 4, however, it is proved that joint use of liability and safety regulation can indeed be optimal if wealth varies among injurers. This seems to be a plausible and simple reason for joint use of liability and regulation which may also be more important than enforcement errors. ${ }^{4}$ In addition, it is shown that in this case the regulatory standard should be set at a level which is smaller than

\footnotetext{
${ }^{3}$ See Calabresi (1970), Brown (1973), and the more recent models of Endres (1989) and Kaplow and Shavell (1996). For surveys see Schäfer and Ott (1995, pp. 95-319), Shavell (1987), and Emons (1990).

${ }^{4}$ The role of limited wealth is by now well recognized in the law and economics literature, but the possible importance of individuals' heterogeneity with respect to wealth limitations has mostly been neglected. See Polinsky and Shavell (1991) for a notable exception, albeit in a quite different context.
} 
the standard which is socially optimal if regulation alone is used..$^{5}$ Finally, some concluding remarks follow in the last section. It is argued that the main result of Section 3, which contradicts Shavell's (1984a) and Kolstad, Ulen and Johnson's (1990) view that joint use of liability and regulation can enhance social welfare, may well re-emerge if more general forms of regulation are considered. All proofs have been relegated to the appendix.

\section{The basic model}

In the model, risk-neutral parties engage in hazardous economic activities from which accidents can occur. ${ }^{6}$ According to the classification of Shavell (1987), only unilateral accidents are considered, i.e., no decisions have to be made by potential victims. However, potential injurers can reduce the probability of causing an accident by taking precaution. Let $x \in[0,1]$ denote the verifiable level of care chosen by an injurer. Care is normalized so that an accident will be caused by this injurer with probability $1-x$. An injurer's cost of taking precaution is given by the function $C(x)$, which is assumed to be strictly increasing and strictly convex, where $C(0)=C^{\prime}(0)=0$ and $\lim _{x \rightarrow 1} C^{\prime}(x)=\infty .^{7}$ Let $h$ be the magnitude of harm if an accident occurs. When an injurer decides how much care to take, the harm he may cause is known only to himself. Yet, it is common knowledge

\footnotetext{
${ }^{5}$ This confirms central conjectures of Shavell (1984a) and Kolstad, Ulen, and Johnson (1990), even though the underlying logic will be different.

${ }^{6}$ It will be assumed throughout that the utility which an injurer derives from engaging in his activity is sufficiently large, so that the decision whether or not to engage in the activity need not be modelled explicitly. Cf. Shavell (1987).

${ }^{7}$ While the costs of taking care are nonpecuniary, they are measured in monetary units. This formalization has an advantage over the one chosen by Shavell (1984a), where one might be tempted to interpret expenditures on care to be monetary, although only the damage payments are subject to wealth constraints.
} 
that $h$ is distributed according to a cumulative distribution function $F(h)$ which is supposed to be strictly increasing on the unit interval. ${ }^{8}$ Once an accident has occurred, $h$ can be verified. ${ }^{9}$

The socially optimal amount of precaution that an injurer of type $h$ should choose, $x^{*}(h)$, can be obtained by minimizing the sum of the costs of care and of harm done,

$$
C(x)+(1-x) h
$$

Thus, the socially optimal level of care is characterized by the first-order condition

$$
C^{\prime}\left(x^{*}(h)\right)=h
$$

which of course means that the marginal cost of precaution equals the harm that the injurer causes if an accident occurs. Implicit differentiation shows that the function $x^{*}(h)$ is strictly increasing,

$$
\frac{d x^{*}(h)}{d h}=\frac{1}{C^{\prime \prime}\left(x^{*}(h)\right)}>0 .
$$

I say that 'the first best is achieved' if an injurer of type $h$ chooses the socially optimal level of care, $x^{*}(h)$.

\section{Wealth does not vary among injurers}

The first policy instrument to be considered is ex ante safety regulation. This instrument is completely characterized by a single regulatory minimum standard

\footnotetext{
${ }^{8}$ The assumption that $h \in[0,1]$ is made for expositional purposes only. No additional insights could be gained by assuming $h \in[a, b]$, where $0 \leq a<b$.

${ }^{9}$ Note that apart from the potential harm, $h$, injurers are identical in every respect, which is a usual assumption in the standard economic model of tort law. Furthermore, notice that there is no interaction among injurers (in particular, the probability that an injurer causes an accident does not depend on the precaution of other injurers). Hence, one can focus on a single representative injurer who is privately informed about his type $h$.
} 
$s \in[0,1]$, to which parties must adhere in order to engage in their activity. Since taking precaution is costly, no injurer will voluntarily choose a higher level of care, so that under regulation each injurer chooses $x_{R}=s$, independent of his type $h$. Therefore, the socially optimal standard can be found by minimizing expected total costs

$$
T C_{R}(s)=E(C(s)+(1-s) h)
$$

The first-order condition is given by

$$
C^{\prime}\left(s_{R}\right)=E(h)
$$

which says that the marginal cost of care equals the expected harm. The optimal regulatory standard is hence given by $s_{R}=x^{*}(E(h))$, i.e., by the level of precaution that would be socially optimal for an injurer who could cause the average level of harm, $E(h)$.

The second instrument to be analyzed is ex post liability. It will be postulated throughout that liability is strict, so that an injurer who has caused an accident is required to pay damages $L$ to the victim, regardless of how much care has been taken. ${ }^{10}$ Assume that an injurer might escape suit and let $q$ denote the probability of suit, where $0<q \leq 1 .{ }^{11}$ Furthermore, let $y$ denote the injurer's level of wealth, so that he will actually pay only $\min \{L, y\}$ if an accident occurs and suit is brought. Then the injurer's problem is to minimize

$$
C(x)+(1-x) q \min \{L, y\}
$$

over the amount of care, $x$. Hence, the first-order condition reads $C^{\prime}\left(x_{L}\right)=$ $q \min \{L, y\}$, and the level of care under strict liability is thus given by $x_{L}=$

\footnotetext{
${ }^{10}$ Strict liability is considered in order to facilitate comparison with Shavell (1984a). Under the negligence rule, the formulae would look slightly more complicated, but qualitatively the main insights would still be true. See Summers (1983) and Shavell (1986).

${ }^{11}$ Note that by assumption $q$ does not depend on the identity of the injurer.
} 
$x^{*}(q \min \{L, y\})$. Anticipating the behavior of injurers, it is possible to calculate the optimal magnitude of liability: ${ }^{12}$

Lemma 1 The optimal magnitude of liability is given by $L^{*}=\frac{1}{q} h$.

In what follows, it is always assumed that the magnitude of liability is given by $L^{*}$. Since sole use of liability can obviously implement the first-best if the injurer's wealth is sufficiently large, only the non-trivial case $y \leq \frac{1}{q}$ will be considered. Then the expected total costs under liability are given by

$$
\begin{aligned}
T C_{L}(y)= & \int_{0}^{q y}\left(C\left(x^{*}(h)\right)+\left(1-x^{*}(h)\right) h\right) d F(h) \\
& +\int_{q y}^{1}\left(C\left(x^{*}(q y)\right)+\left(1-x^{*}(q y)\right) h\right) d F(h) .
\end{aligned}
$$

Finally, joint use of regulation and liability will be analyzed. Due to regulation, the injurer's level of precaution must not be smaller than some standard, $s>0$. Only sometimes will liability induce injurers to overcomply with respect to this standard. Therefore, two cases have to be considered. If $s>x^{*}(q y)$, joint use of regulation and liability is in fact equivalent to exclusive use of regulation (recall that $x_{L}$ is never larger than $x^{*}(q y)$ ), so that the expected social costs are given by $T C_{R}(s)$. If however $s \leq x^{*}(q y)$, the injurer chooses $x_{J}=\max \left\{s, x_{L}\right\}=$ $\max \left\{s, x^{*}(\min \{h, q y\})\right\}$ and expected total costs read

$$
\begin{aligned}
T C_{J}(s, y)= & \int_{0}^{C^{\prime}(s)}(C(s)+(1-s) h) d F(h) \\
& +\int_{C^{\prime}(s)}^{q y}\left(C\left(x^{*}(h)\right)+\left(1-x^{*}(h)\right) h\right) d F(h) \\
& +\int_{q y}^{1}\left(C\left(x^{*}(q y)\right)+\left(1-x^{*}(q y)\right) h\right) d F(h) .
\end{aligned}
$$

It is now possible to compare the expected social costs which arise in the three different regimes. The following proposition shows that the essential finding of

\footnotetext{
${ }^{12}$ The damage multiplier $\frac{1}{q}$ is sometimes called punitive multiple (see Cooter and Ulen, 1988, or Cooter, 1991).
} 
Shavell (1984a), which says that joint use of regulation and liability can be strictly welfare increasing, does not hold, provided that the magnitude of liability is given by Lemma $1 .^{13}$

Proposition 1 Assume that the level of wealth, $y$, is the same for each injurer. If $y$ is smaller than a certain threshold value $\hat{y}$, where $0<\hat{y}<\frac{E(h)}{q}$, it is optimal to use regulation as the sole means of controlling risk. Otherwise, it is optimal to use liability only. In particular, social welfare can never be increased by the joint use of regulation and liability.

Loosely speaking, the main argument is as follows. Recall that (by Lemma 1) liability alone can implement the socially optimal level of care if $h \leq q y$. Additional regulation could only decrease welfare in this case, by making injurers choose too much precaution. It is true that liability cannot implement a level of precaution larger than $x^{*}(q y)$. However, if it is optimal to implement some $x>x^{*}(q y)$ at the cost of inefficiently high precaution levels for injurers who can cause small harm only, this can be achieved by regulation alone. In this case, the additional use of liability would simply have no effect. Hence, joint use of regulation and liability can never be socially advantageous if wealth $y$ is the same for each injurer. This result is in sharp contrast with Shavell (1984a).

\section{Wealth varies among injurers}

Now assume that wealth varies among injurers. For simplicity, suppose that there are only two different wealth classes, poor people with wealth $y_{p}$ and rich people

\footnotetext{
${ }^{13}$ Shavell (1984a) assumes $L=h$ and $q<1$. He briefly considers increasing liability in his footnote 9 , but suggests that the essential nature of his results would be the same. Note that all results in the present paper are also valid for $q=1$, the case most often considered in the literature. In this case, the punitive multiple disappears $\left(L^{*}=h\right)$.
} 
with wealth $y_{r}$, where $0<y_{p}<y_{r} \leq \frac{1}{q}$. Let the proportion of poor people be given by $p \in(0,1) .{ }^{14}$ Assume that the same instruments are available as in last section. If regulation alone is used, the optimal standard is still given by $s_{R}=x^{*}(E(h))$, and the expected social costs $T C_{R}\left(s_{R}\right)$ remain unchanged. While the optimal magnitude of liability continues to be $L^{*}=\frac{h}{q}$, the expected social costs if liability alone is employed are now given by

$$
p T C_{L}\left(y_{p}\right)+(1-p) T C_{L}\left(y_{r}\right) .
$$

One might be tempted to think that, in the spirit of Proposition 1, regulation alone is optimal whenever $T C_{R}\left(s_{R}\right)$ is smaller than this expression. This is, however, not true. In fact, the following proposition says that if injurers are heterogeneous with respect to their wealth, there are situations in which it may indeed happen that the joint use of regulation and liability leads to strictly smaller expected social costs than the exclusive use of one of these instruments.

Proposition 2 Let the wealth of poor injurers be given by $y_{p}<\hat{y}$, and the wealth of rich injurers by $y_{r}>\frac{E(h)}{q}$. If the proportion of poor injurers, $p$, is sufficiently large, then expected total costs are strictly smaller under joint use of regulation and liability than under either regulation or liability alone.

In order to better understand the result, note that the assumptions in Proposition 2 confine attention to the interesting situation in which regulation would be preferred if there were only poor people, while liability would be preferred if there were only rich people (see Proposition 1). In this situation, joint use of both

\footnotetext{
${ }^{14}$ It is assumed that an injurer's wealth has no influence on the level of harm he might cause. Note that the case of two wealth classes is sufficient to show that joint use of liability and regulation can be strictly welfare enhancing. One could of course consider the case of more than two wealth classes, but this would only complicate the exposition without yielding any additional economic insights.
} 
instruments can increase social welfare by making poor injurers stick to the regulatory standard $s_{R}$ and by inducing rich injurers to take optimal care over some intermediate range of $h$. It is true that rich injurers with very small values of $h$ choose $s_{R}$, and rich injurers with very high values of $h$ choose $x^{*}\left(q y_{r}\right)$. Yet, whenever (in the situation considered here) exclusive regulation is better than exclusive liability, then joint use must inevitably be even better, since under regulation all rich injurers would choose $s_{R}$.

Given that joint use of liability and regulation with standard $s_{R}$ is in fact socially advantageous, one may ask whether the expected total costs could be further decreased by choosing a regulatory standard different from the one which is optimal under exclusive regulation. It turns out that this is indeed the case, as the following proposition demonstrates.

Proposition 3 If under the assumptions of the previous proposition joint use of regulation and liability is strictly welfare-improving, the optimal standard $s_{J}$ will be strictly smaller than $s_{R}$, the standard which is optimal under sole use of regulation.

The intuitive explanation for the result is straightforward. In the considered situation, the behavior of poor injurers is controlled by regulation only. Hence, if there were only poor injurers, $s=s_{R}$ would indeed be the optimal standard (see Section 3). Yet, the behavior of rich injurers would ideally be controlled by liability only. If there were only rich injurers, the optimal standard would thus be zero. Therefore, it is not surprising that the standard which is optimal given that there are both poor and rich injurers lies between zero and $s_{R}$. 


\section{Conclusion}

In this paper a certain class of rules (namely, strict liability, safety regulation in the sense of a uniform minimum standard, and the combination of both) has been taken as exogenously given. Rational behavior under these rules has been analyzed and the socially optimal rule within the given class has been determined. In fact, most law and economics papers proceed in this way, and it is not unusual to discuss informational requirements of the different rules only casually. ${ }^{15}$ In the present model, one obviously has to assume that the level of care is verifiable, since otherwise regulation were not possible. Furthermore, liability requires that the harm done and the level of wealth are verifiable.

Given these assumptions there are of course rules which can implement the first best: If an accident occurs, the court can verify whether the injurer has chosen the optimal amount of care, $x^{*}(h)$. Hence, injurers could easily be induced to take optimal precaution with the help of non-monetary sanctions such as imprisonment (or 'shooting them', a common receipt in implementation theory, see Moore, 1992). ${ }^{16}$ Alternatively, the first best could be achieved by sufficiently rewarding the injurer whenever an accident happens and socially optimal precaution has been taken. While considerations that are not explicitly modelled might render such alternatives unrealistic, it remains unclear how to judge which rules have to be taken into account.

In any case, one possible modification of the analyzed rules comes to mind

\footnotetext{
${ }^{15}$ In contrast, from a mechanism design point of view one should start with the informational assumptions and endogenously determine the class of rules which is feasible under these assumptions. This distinction is related to the one between the recent theory of incomplete contracts (see Hart, 1995) and traditional complete contracts theory. Cf. also Schmitz (2001).

${ }^{16}$ Note that sufficiently high sanctions are implicitly assumed to be possible in order to enforce the regulatory standard.
} 
which may deserve further discussion. Assume that when wealth varies among injurers and joint use of regulation and liability is welfare-improving according to Proposition 2, the regulatory standard may now depend on $y$. In this case, the arguments of Proposition 1 become valid again and it is never optimal to control the behavior of an injurer by liability and regulation simultaneously. Instead, poor injurers will have to comply to the optimal regulatory standard $s_{R}$, while the behavior of rich injurers will be controlled by liability only. In other words this means that poor people face a standard of $s_{R}>0$, while rich people face a standard of 0 , which of course might again be unacceptable since one could argue that it violates the equal protection clause. This discussion clearly illustrates that more attention should be devoted to a careful explanation of why the restriction to certain exogenously given rules may be reasonable. 


\section{Appendix}

\section{Proof of Lemma 1.}

Note first that $L^{*}=\frac{1}{q} h$ induces the injurer to take optimal precaution, $x_{L}=$ $x^{*}(h)$, in the case $\frac{h}{q} \leq y$.

Next, consider the case $\frac{h}{q}>y$. In this case nothing would be gained if $L$ were larger than $\frac{h}{q}$, since the injurer would still choose $x_{L}=x^{*}(q y)$. It remains to show

that $L<\frac{h}{q}$ could not lead to smaller social costs. If $y \leq L<\frac{h}{q}$, the injurer again would choose $x^{*}(q y)$. If $L<y$, the injurer would choose $x^{*}(q L)<x^{*}(q y)$, which means that the social costs $C(x)+(1-x) h$ would be higher (since they are convex, minimized by $x^{*}(h)$ and $\left.x^{*}(q y)<x^{*}(h)\right)$.

\section{Proof of Proposition 1.}

The proof consists of three steps, the first of which shows that there is a unique threshold value $\hat{y}>0$, such that regulation is socially better than liability if $y$ is smaller than $\hat{y}$, and liability is better than regulation otherwise. The second step establishes $\hat{y}<\frac{E(h)}{q}$. Finally, it is demonstrated in the third step that the simultaneous use of liability and regulation cannot increase social welfare.

(i) Regulation is clearly better than liability if injurers have no wealth (formally, $s_{R}=x^{*}(E(h))>0$ implies $\left.T C_{L}(0)=T C_{R}(0)>T C_{R}\left(s_{R}\right)\right)$. On the other hand, if $y=\frac{1}{q}$, which means that the wealth constraint is never binding, liability achieves the socially optimal solution, so that $T C_{L}\left(\frac{1}{q}\right)<T C_{R}\left(s_{R}\right)$. A simple intermediate value argument can now be applied. Note that $T C_{L}(y)$ is a continuous function which is strictly decreasing:

$$
\begin{aligned}
\frac{d}{d y} T C_{L}(y) & =\int_{q y}^{1}\left(C^{\prime}\left(x^{*}(q y)\right)-h\right) \frac{d x^{*}(q y)}{d y} d F(h) \\
& =\frac{q}{C^{\prime \prime}\left(x^{*}(q y)\right)} \int_{q y}^{1}(q y-h) d F(h)<0
\end{aligned}
$$


where (1) and (2) have been used. Hence, there exists a unique cut-off value $\hat{y} \in\left(0, \frac{1}{q}\right)$, such that regulation is preferred if $y$ is smaller than $\hat{y}$, and liability is preferred otherwise.

(ii) In order to proof $\hat{y}<\frac{E(h)}{q}$, it must be shown that $T C_{R}\left(s_{R}\right)-T C_{L}\left(\frac{E(h)}{q}\right)>0$. Using (3), this condition can be rewritten as

$$
\begin{aligned}
& \int_{0}^{E(h)}\left(C\left(x^{*}(E(h))\right)+\left(1-x^{*}(E(h))\right) h\right) d F(h) \\
> & \int_{0}^{E(h)}\left(C\left(x^{*}(h)\right)+\left(1-x^{*}(h)\right) h\right) d F(h),
\end{aligned}
$$

which is clearly true due to the definition of $x^{*}(h)$.

(iii) In order to see that joint use of liability and regulation (with some given standard $s$ ) cannot improve social welfare, consider first the case $s>x^{*}(q y)$. Then joint use is equivalent to the sole use of regulation, since liability cannot induce the injurer to choose more care than $x^{*}(q y)$. Behavior would in fact be controlled by regulation only, so that additional liability would simply be superfluous. The case $s=0$ is obviously equivalent to exclusive use of liability. It remains to show that joint use of liability and regulation with $0<s \leq x^{*}(q y)$ cannot be optimal. In this case, expected total costs are given by $T C_{J}(s, y)$. By the definition of $x^{*}(h)$, this expression is clearly larger than $T C_{L}(y)$, so that total costs could be reduced by making use of liability only. Hence, it can never be socially advantageous to use a combination of liability and regulation.

\section{Proof of Proposition 2.}

In the first step of the proof, the expected total costs resulting from the exclusive use of either regulation or liability are compared. If this comparison favors regulation, social costs can be strictly reduced by additional liability, as will be argued in the second step. 
(i) Exclusive use of regulation is socially better than exclusive use of liability whenever

$$
p T C_{L}\left(y_{p}\right)+(1-p) T C_{L}\left(y_{r}\right) \geq T C_{R}\left(s_{R}\right)
$$

which is equivalent to $p \geq \hat{p}$, where

$$
\hat{p}=\frac{T C_{R}\left(s_{R}\right)-T C_{L}\left(y_{r}\right)}{T C_{L}\left(y_{p}\right)-T C_{L}\left(y_{r}\right)} .
$$

Note that under the assumptions of the proposition, $0<\hat{p}<1$ is guaranteed.

(ii) Consider the case $\hat{p}<p<1$. Since $x^{*}\left(q y_{p}\right)<x^{*}(q \hat{y})<x^{*}(E(h))=s_{R}$ and $x^{*}\left(q y_{r}\right)>x^{*}(E(h))=s_{R}$, the expected social costs under joint use of liability and regulation with standard $s_{R}$ are given by

$$
p T C_{R}\left(s_{R}\right)+(1-p) T C_{J}\left(s_{R}, y_{r}\right) .
$$

Hence, it remains to show that this expression is strictly smaller than $T C_{R}\left(s_{R}\right)$. This is clearly the case, since

$$
\begin{aligned}
& T C_{R}\left(s_{R}\right)-T C_{J}\left(s_{R}, y_{r}\right) \\
= & \int_{E(h)}^{q y_{r}}\left(C\left(s_{R}\right)+\left(1-s_{R}\right) h-\left(C\left(x^{*}(h)\right)+\left(1-x^{*}(h)\right) h\right)\right) d F(h) \\
& +\int_{q y_{r}}^{1}\left(C\left(s_{R}\right)+\left(1-s_{R}\right) h-\left(C\left(x^{*}\left(q y_{r}\right)\right)+\left(1-x^{*}\left(q y_{r}\right)\right) h\right)\right) d F(h)
\end{aligned}
$$

must be strictly positive due to the definition of $x^{*}(h)$ and due to the fact that $C(x)+(1-x) h$ is decreasing for $x<x^{*}(h)$.

\section{Proof of Proposition 3.}

Consider again the situation of Proposition 2, so that joint use of liability and regulation with standard $s_{R}$ is socially better than exclusive use of liability or regulation alone. The optimal standard $s_{J}$ cannot be smaller than $x^{*}\left(q y_{p}\right)$, since otherwise liability alone would have been optimal. Similarly, $s_{J}$ cannot be 
larger than $x^{*}\left(q y_{r}\right)$, because this would be equivalent to pure regulation and hence contradict the fact that $s_{R}=x^{*}(E(h))$ is smaller than $x^{*}\left(q y_{r}\right)$. In the relevant range of $s$, expected total costs are thus given by

$$
p T C_{R}(s)+(1-p) T C_{J}\left(s, y_{r}\right)
$$

The first derivative of this expression with respect to $s$ equals

$$
p\left(C^{\prime}(s)-E(h)\right)+(1-p) \int_{0}^{C^{\prime}(s)}\left(C^{\prime}(s)-h\right) d F(h) .
$$

The second derivative is given by

$$
\left[p+(1-p) F\left(C^{\prime}(s)\right)\right] C^{\prime \prime}(s)>0
$$

so that the expected total costs are convex in $s$. In order to prove that the optimal standard $s_{J}$ is smaller than $s_{R}$, it has to be shown that the first derivative is positive at $s=s_{R}$. Using (3), it is straightforward to see that

$$
\begin{aligned}
& p\left(C^{\prime}\left(s_{R}\right)-E(h)\right)+(1-p) \int_{0}^{C^{\prime}\left(s_{R}\right)}\left(C^{\prime}\left(s_{R}\right)-h\right) d F(h) \\
= & (1-p) \int_{0}^{E(h)}(E(h)-h) d F(h),
\end{aligned}
$$

which obviously is positive. 


\section{References}

Brown, John Prather (1973). Toward an Economic Theory of Liability. Journal of Legal Studies 2: 323-350.

Calabresi, Guido (1970). The Costs of Accidents. New Haven: Yale University Press.

Cooter, Robert D. (1991). Economic Theories of Legal Liability, Journal of Economic Perspectives 5: 11-30.

Cooter, Robert D. and Ulen, Thomas S. (1988). Law and Economics. Glenview, IL: Scott, Foresman.

Endres, Alfred (1989). Liability and Information. Journal of Institutional and Theoretical Economics 145: 249-274.

Emons, Winand (1990). Some Recent Developments in the Economic Analysis of Liability Law: An Introduction. Journal of Institutional and Theoretical Economics 146: 237-248.

Ewerhart, Christian And Schmitz, Patrick W. (1998). Ex Post Liability for Harm vs. Ex Ante Safety Regulation: Substitutes or Complements? Comment. American Economic Review 88: 1027.

Hart, Oliver (1995). Firms, contracts, and financial structure. Oxford: Clarendon Press.

Kaplow, Louis and Shavell, Steven (1996). Accuracy in the Assessment of Damages. Journal of Law and Economics 39: 191-210.

Kolstad, Charles D., Ulen, Thomas S., and Johnson Gary V. (1990). Ex Post Liability for Harm vs. Ex Ante Safety Regulation: Substitutes or Complements? American Economic Review 80: 888-901. 
Moore, John (1992). Implementation, Contracts and Renegotiation in Environments with Symmetric Information. In: Laffont, J.-J. (ed.), Advances in Economic Theory. Cambridge, University Press.

Polinsky, A. Mitchell and Shavell, Steven (1991). A Note on Optimal Fines When Wealth Varies Among Individuals. American Economic Review 81: $618-621$.

Rose-Ackerman, Susan (1991). Regulation and the Law of Torts. American Economic Review 81: 54-58.

Schäfer, Hans-Bernd And Ott, Claus (1995). Lehrbuch der ökonomischen Analyse des Zivilrechts, 2. Auflage. Berlin, Heidelberg: SpringerVerlag.

Schmitz, Patrick W. (2001). The Hold-up Problem and Incomplete Contracts: A Survey of Recent Topics in Contract Theory. Bulletin of Economic Research 53: 1-17.

Schwarze, Reimund (1996). The Role of Common Law in Environmental Policy: Comment. Public Choice 89: 201-205.

Shavell, Steven (1984a). A Model of the Optimal Use of Liability and Safety Regulation. Rand Journal of Economics 15: 271-280.

Shavell, Steven (1984b). Liability for Harm versus Regulation of Safety. Journal of Legal Studies 13: 357-374.

Shavell, Steven (1986). The Judgement Proof Problem. International Review of Law and Economics 6: 45-58.

Shavell, Steven (1987). The Economic Analysis of Accident Law. Cambridge: Harvard University Press. 
Söllner, Fritz (1994). The Role of Common Law in Environmental Policy. Public Choice 80: 69-82.

Söllner, Fritz (1996). Common Law and the Environment: Reply. Public Choice 89: 207-209.

Summers, John (1983). The Case of the Disappearing Defendant: An Economic Analysis. University of Pennsylvania Law Review 132: 145-185.

Weitzman, Martin L. (1974). Prices vs. Quantities. Review of Economic Studies 41: 447-491.

Wittman, Donald (1977). Prior Regulation versus Post Liability: The Choice between Input and Output Monitoring. Journal of Legal Studies 6: $193-212$. 